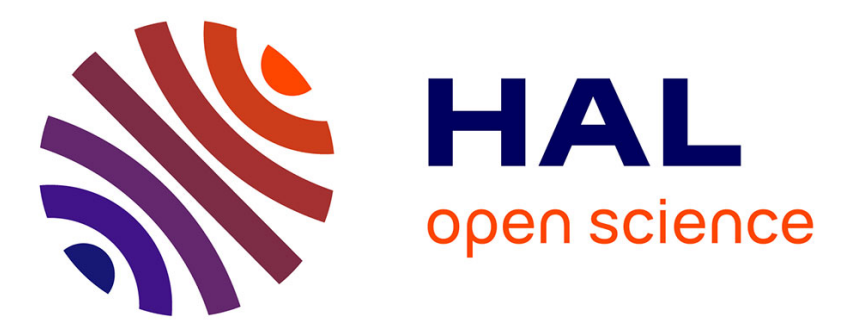

\title{
Calculations of the charge distribution in dodecyltrimethylammonium: a quantum chemical investigation
}

Benoît Minisini, Sylvain Chavand, Rudolph Barthelery, François Tsobnang

\section{- To cite this version:}

Benoît Minisini, Sylvain Chavand, Rudolph Barthelery, François Tsobnang. Calculations of the charge distribution in dodecyltrimethylammonium: a quantum chemical investigation. Journal of Molecular Modeling, 2009, 16 (6), pp.1085-1092. 10.1007/s00894-009-0620-0 . hal-00568336

\section{HAL Id: hal-00568336 https://hal.science/hal-00568336}

Submitted on 23 Feb 2011

HAL is a multi-disciplinary open access archive for the deposit and dissemination of scientific research documents, whether they are published or not. The documents may come from teaching and research institutions in France or abroad, or from public or private research centers.
L'archive ouverte pluridisciplinaire HAL, est destinée au dépôt et à la diffusion de documents scientifiques de niveau recherche, publiés ou non, émanant des établissements d'enseignement et de recherche français ou étrangers, des laboratoires publics ou privés. 


\section{Editorial Manager(tm) for Journal of Molecular Modeling Manuscript Draft}

\section{Manuscript Number: JMM0790R1}

Title: Calculations of the charge distribution in dodecyltrimethylammonium: a quantum chemical investigation

Article Type: Original paper

Keywords: dodecyltrimethylammonium; electrostatic charges; quantum calculations

Corresponding Author: Dr benoit minisini, Ph D

Corresponding Author's Institution: ISMANS

First Author: benoit minisini, $\mathrm{Ph} \mathrm{D}$

Order of Authors: benoit minisini, Ph D; sylvain chavand; rudolph barthelery; françois tsobnang

Abstract: In this work we report the atomic partial charges evaluated on dodecyltrimethylammonium. The values obtained from 17 quantum methods (CHELP, CHELPG, MK, NPA at (HF, LDA, PBE, B3LYP)//6-31G++(d,p) level and APT at B3LYP//6-31G++(d,p)) on the molecule optimized at B3LYP/6-31G++(d,p) level were compared to two semiempirical methods (Gasteiger and Qeq) and the commercial force field PCFF. All the methods based on quantum calculation gave a positive charge delocalized on at least the first four alkyl groups of the tail. However, those deriving partial charges from the electrostatic potential gave an unrealistic set of alternative positive and negative alkyl group charges along the tail. In comparison, the NPA and APT methods lead to a monotonous decrease in the partial charges from the third alkyl group and agreed closely tothe representation of the electrostatic potential mapped onto the van der Waals surface. The choice of the exchange correlation treatment does not drastically influence the atomic partial charges.

Response to Reviewers: Dear reviewer

Thank you very much for your work and your suggestions.

The correction madeare in bold in the new proposal. Please find your comment and my answers.

Best regards

Benoit Minisini

1) The authors refer throughout the paper to what I assume are various ammonium ions, but they never use the word ion. To say ....ammonium is not enough; ammonium is not a molecule. They need to identify them as ions.

Ion has been added after ammonium

2) They should show the structure of the dodecyltrimethylammonium ion in the Introduction.

The chemical formula has been added in page 3 
3) It is all right to use the 0.002 contour to represent the molecular surface, but this is not the same as a van der Waals surface, and should not be so labeled. The van der Waals surface would have the van der Waals radii of the individual atoms. There is no reason to believe that the 0.002 does so.

The comment about the van der Waals surface has been deleted.

4) The blue region in the electrostatic potential plot is on the right, not the left (as is stated on page 4).

Modification has been made

5) There are some errors on page 6 that should be corrected. In line 13, the sentence should begin "With the exception..."

In line 16, the second word should be "close" In the last line, there should be a space between "an" and "important"

Correction has been made.

Finally, the authors might be interested to not some articles concerning charge alternation in carbon chains that appeared a number of years ago. There was one by Warnheim, Politzer et al in J. Phys. Chem . around 1982, which followed earlier work by Pople et al.

Thank you very much for this reference. It was not easy for me to have access to this article. That's the reason why I was so long to correct the draft. I included in the text some sentences about the work done by the authors and their conclusion. 


\title{
Calculations of the charge distribution in dodecyltrimethylammonium: a quantum chemical investigation
}

Received: 02.04.2009 / Accepted: 28.10.2009

Benoît Minisini $^{\bowtie}$, Sylvain Chavand, Rudolph Barthelery, and François Tsobnang

Institut Supérieur des Matériaux et Mécaniques Avancés du Mans, 44 Av. Bartholdi, 72000 Le Mans, France

${ }^{\circledR}$ Tel:33 (0)2 432140 00; Fax: 33 (0)2 43214039 E-Mail: bminisini@ismans.fr

\begin{abstract}
In this work we report the atomic partial charges evaluated on dodecyltrimethylammonium ion. The values obtained from 17 quantum methods (CHELP, CHELPG, MK, NPA at (HF, LDA, PBE, B3LYP)//6-31G++(d,p) level and APT at B3LYP//6-31G++(d,p)) on the molecule optimized at B3LYP/6-31G++(d,p) level were compared to two semiempirical methods (Gasteiger and Qeq) and the commercial force field PCFF. All the methods based on quantum calculation gave a positive charge delocalized on at least the first four alkyl groups of the tail. However, those deriving partial charges from the electrostatic potential gave an unrealistic set of alternative positive and negative alkyl group charges along the tail. In comparison, the NPA and APT methods lead to a monotonous decrease in the partial charges from the third alkyl group and agreed closely to the representation of the electrostatic potential mapped onto the 0.002 au isodensity surface. The choice of the exchange correlation treatment does not drastically influence the atomic partial charges.
\end{abstract}

Keywords Dodecyltrimethylammonium · Electrostatic charges · Quantum calculations 


\section{Introduction}

Since the nineties there has been a growing interest in cationic surfactants due to their important implications in new technologies such as the room temperature ionic liquids [1] or nanomaterials [2]. From the same date the molecular modelling simulations were intensively carried out for different purposes well detailed in different reviews [3-5]. Among the different methods available, in spite of the simulated size and time limitations, atomistic methods are still considered as the most precise techniques to study surfactants systems. The main characteristics of the atomistic method rely on an accurate treatment of the van der Waals and Coulombic interactions. Therefore, the parameterization of the partial atomic charges is crucial in the evaluation of numerical results when a quantitative comparison with experimental data is required. This statement is perfectly illustrated by the works of Heinz et al. dealing with the experimental determination of the partial atomic charges of silicates [6] and the impact of the partial charges on the surface energy calculations [7]. However from our knowledge, there are no any experimental techniques available to measure the electrostatic charges of surfactants. Consequently, numerical methods remain the most accurate means to evaluate these charges. In general, the charges of alkylammonium ions are directly taken from existing force fields such as COMPASS [8-11] or ffgmx [12]. When UFF [13-17] and Dreiding [16-23] force fields are used the charges are often evaluated from the charge equilibration method $[14,15,18-22]$. Otherwise, the charges for $\mathrm{NH}_{4}{ }^{+}, \mathrm{CH}_{3} \mathrm{NH}_{3}{ }^{+}$and $\left(\mathrm{CH}_{3}\right)_{4} \mathrm{~N}^{+}$evaluated by Jorgensen et Gao [24] in 1986 owing to a population analysis on wave functions obtained at $\mathrm{HF} / 6-31 \mathrm{G}^{*}$ level are extensively used for more recent atomistic simulation studies [25-29]. At the beginning of the nineties, Böcker et al. [30] used the same level of theory to evaluate the charge distribution on ethyltrimethylammonium ion, once again their results were used as a reference for more recent atomistic simulation studies [31-32]. More recently a method deriving the charge from electrostatic potential calculated at a HF/6$31 \mathrm{G}^{*}$ level was used to evaluate the atomic partial charges of hexylammonium [34], hexytrimethylammoium [34], dodecyltrimethylammonium $[33,34]$ and octyltrimethylammonium [35] ions. However, as far as we know, the only results including the correlation effects were obtained for cetylpiridinium ion [36] from B3LYP/SVP calculations.

From these previous works we can notice an important dispersion of the values of the atomic charges. For example, the nitrogen charges cover a range of values from -0.628e [37] to 0.20e [34] for alkyltrimethylammonium ion. Moreover, the charges were in some cases only 
calculated for the headgroup and consequently the charges of the alkyl group of the tail were fixed at zero. However, from a study of charge distribution in ionic surfactant performed with semiempirical methods, Huibers [38] have shown that $10 \%$ of the positive charge could reside on the tail.

Consequently, the aim of this work was to compare the charge distributions in dodecyltrimethylammonium ion $\left(\mathbf{C H}_{3}\left(\mathbf{C H}_{2}\right)_{11}\left(\mathbf{C H}_{3}\right)_{3} \mathbf{N}^{+}\right)$obtained with different methods. The wave functions and the electrostatic potential determinations were performed using HF, MP2, LDA, GGA, B3LYP theories and the 6-31++G(d,p) basis set on geometry previously optimized with the B3LYP theory and $6-31++\mathrm{G}(\mathrm{d}, \mathrm{p})$ basis set. After a comparison of the electrostatic potential, we compared the atomic partial charges calculated according to three methods from electrostatic potentials, natural population analysis and the atomic polar tensor analysis. These results were also compared to those obtained from charge equilibration methods and those available in COMPASS force field.

\section{Methodology}

The linear geometry of dodecyltrimethylammonium ion was optimized using the GAUSSIAN98 [39] program at the B3LYP/6-31++g(d,p) level. The SCF convergence on the density matrix was set up at $10^{-8}$ a.u whereas the Berny algorithm [40] was used for the optimization with the criteria for convergence being a maximum force less than $4510^{-5} \mathrm{a}$.u and a rms force less than $310^{-4}$ a.u. Then the molecular electrostatic potential(MEP) and the atomic population were evaluated, using Hartree-Fock (HF) [41], second order Moller-Plesset perturbation theory (MP2) [42], local density approximation(LDA) [43], generalized gradient approximation(GGA) with the PBE [44] exchange correlation functional and B3LYP [45-46] hybrid exchange correlation functional with $6-31++\mathrm{g}(\mathrm{d}, \mathrm{p})$ basis set, on the previously optimized geometry using the GAUSSIAN03 [47] program. Population analyses were first evaluated using three methods based on the fit of the molecular electrostatic potential under the constraint of reproducing the dipole moment. The CHELP [48] method was used with the atomic radii defined by Francl and five shells leading to 2892 points to fit. The CHELPG [49] method was used with the atomic radii defined by Breneman. The grid spacing and the outer grid radius were 0.3 Bohr and 2.8 Bohr respectively resulting in 25882 points to fit. Concerning the MK $[50,51]$ method, 4 shells, with scaling factor ranging from 1.4 to 2 , were 
used around the van der Waals envelope defined by the Merz-Kollman atomic radii. The default density of grid points provided 1861 points used for the fitting. The Natural Population Analysis $[52,53]$ (NPA) and the Cioslowki's Atomic Polar Tensor [54, 55] (APT) were also considered. These results were compared to less demanding methods such as the charge equilibration methods available in the Materials Studio software package[56] (version 4.2). Qeq_charge 1.1 [57] and Gasteiger 1.0 [58] methods were used with a convergence limit of $5^{*} 10^{-6}|\mathrm{e}|$.

\section{Results and discussion}

The structure of the optimized dodecyltrimethylammonium ion and the molecular electrostatic potential mapped on the electron density surface is presented in Fig. 1. An isodensity value of $0.002{\mathrm{e} / \mathrm{Bohr}^{3}}^{3}$ was chosen. This mapped surface was created from the results obtained at B3LYP level with a color scale varying from $0 \mathrm{kcal} \mathrm{mol}^{-1}$ (red) to $127 \mathrm{kcal} \mathrm{mol}^{-1}$ (blue). From these results, the molecule can be clearly divided into three parts. The blue region on the right represents an important electrophilic region with an important positive electrostatic potential. This region includes the nitrogen atoms, the three methyl groups and the two first alkyl groups of the tail. The second region of green color spreading from Met2 to Met7 means that the electrostatic potential is significantly positive in this area. The color in the last region, including the rest of the tail, ranges from greenish yellow to orangish yellow. Consequently, even if it is close to zero the electrostatic potential remains positive even far away from the headgroup. The same division is visible from the results obtained with the two ab initio methods and the three density functional theory methods. However, the net maximal value of the positive electrostatic potential $\left(\mathrm{V}_{\max }\right)$ is different in function of the methods. For an isodensity value of $0.002 \mathrm{e} / \mathrm{bohr}^{3}, \mathrm{~V}_{\max }$ ranges from $124 \mathrm{kcal} \mathrm{mol}^{-1}$ to $132 \mathrm{kcal} \mathrm{mol}^{-1}$. The most positive values are obtained for the HF methods. The value of $\mathrm{V}_{\max }$ is also basis set dependant since $\mathrm{V}_{\text {Max }}$ obtained at the HF/6-31g(d) level is $3 \mathrm{kcal} \mathrm{mol}^{-1}$ higher than the value obtained at the HF/6-31g++(d) level. The lowest value of $V_{\max }$ is obtained with the LDA calculation whereas GGA and hybrid results are close together.

Table 1 and Table 2 present the atomic partial charges evaluated with the different methods. The results obtained with the HF/6-31G(d) are not presented but can be given on demand. As observed in previous works $[34,37]$, the sign of the nitrogen partial charge depends on the 
methods of evaluation. Thus all the methods based on the fitting of the electrostatic potential gave a positive nitrogen value varying from $0.05|\mathrm{e}|$ to $0.32|\mathrm{e}|$ respectively for the MK scheme at the LDA-6.31++G(d,p) level and the CHELP scheme at the HF-6-31++G(d,p) level. The CHELPG nitrogen charge is, on average on the chemistry models, $0.1|\mathrm{e}|$ and $0.17|\mathrm{e}|$ more positive than the values obtained with the CHELP and the MK schemes. This difference is not due to a bad fitting technique since for all these methods, the maximum root mean square (rms) and the relative rms (rrms) are small with the most important value being $0.00233 \mathrm{u}$.a and $0.02751 \%$ respectively. This discrepancy has already been revealed [59] and could be attributed to the different van der Waals radii used in the three schemes, the nitrogen van der Waals radius is $1.50,1.67$ and 1.70 Bohr for the MK, CHELP and CHELPG methods respectively, and the choice of the points used in the least-squares fit of the electrostatic potential. More recent methods such as CHELP-BOW [60] could be tested to see the effect of the inclusion of fit potential points inside the van der Waals surface. On the other hand the nitrogen charges evaluated by NPA and APT are negative. However, the calculated values are less negative than the atomic charges used in commercial force fields. Concerning the charge of the carbon atoms in the methyl groups, all the methods but APT give negative values. We can also notice that the NPA method is the only one which does not make the distinction between the three methyl groups. In all the others methods the atomic charges of the two methyl groups equivalent by mirror symmetry and which include $\mathrm{C}_{1}$ and $\mathrm{C}_{2}$ carbon atoms are the same and are different from the methyl group which include the $\mathrm{C}_{3}$ carbon atom. The negative atomic charges on nitrogen and carbon atoms and the distinction between the three methyl groups do not agree with the distribution of the electrostatic potential visible in Fig. 1. The electrostatic potential is positive all around the headgroup, consequently we expected to have a positive atomic charge on all the atoms present in the headgroup. Moreover, the potential is more positive close to the nitrogen atom than the hydrogen atoms but all the methods gave an atomic charge on the nitrogen atom less important than on the hydrogen atoms.

From a more global point of view, it is interesting to evaluate the global charge of the headgroup to compare this value with the common model using a point unit charge at the headgroup. The $\alpha$ methylene group linking the headgroup to the tail has been included in the reported values. It appears that the charge is less than 1|e| for all the methods. With the exception of the exceptionally low value of $0.379|\mathrm{e}|$ obtained with the semi empirical method Qeq the charges range from $0.78|\mathrm{e}|$ to $0.95|\mathrm{e}|$. This last value calculated with the other semiempirical method Gasteiger1.0 was relatively close to that evaluated with the NPA 
method ranging from 0.92|e| to 0.93|e|. Then, the charges calculated from the APT and CHELP methods ranged from 0.85|e| to 0.87|e| and finally, the MK and CHELPG methods gave some values between $0.77|\mathrm{e}|$ and $0.80|\mathrm{e}|$. In general for the same method of calculation the charges follow this order HF>B3LYP>PBE $>$ LDA. The CHELP method is sensitive to the exchange correlation term with a maximal difference of $0.02|\mathrm{e}|$ contrary of the NPA method with a difference of less than $0.009|\mathrm{e}|$. Consequently, we can say that the charge of the headgroup is more sensitive to the way atomic charges are determined than to the quantum chemical model. The most important discrepancy is that of $17 \%$ between the MK charges and the NPA evaluated at the B3LYP level. It is difficult to know if a method is better than another but we could be sure that such an important difference of charge affects the solubility of the molecule. Compared to a point unit charge model, all of the calculations lead to a delocalization of the positive charge on the tail as observed by Huibers [38] owing to semiempirical quantum calculation. To evaluate the expansion of this distribution we plotted the distribution of the alkyl groups charges along the tail.

Fig. 2 represents the distribution for the charges estimated from the electrostatic potential evaluated at the B3LYP level, the other results give similar shape with slightly different charges and are not represented for better visibility. We can see that the least square fit lead to an odd-even effect with a set of alternative positive and negative alkyl group charges. This behaviour seems unrealistic compared to the electrostatic potential monotonous decreasing along the tail. The concept of charge alternation was put in evidence by Pople and Gordon [61] at the end of the sixty's. P. Poltizer et al. [62] reviewed the controversial experimental and numerical data of the seventy's and performed some calculations on fluorine hydrocarbon at the beginning of the eighty's. Relying on this review, their results and the work of Weinstein et al. [63], they concluded that alternating atomic charges are not inconsistent with an electrostatic potential without sign of alternation. Moreover, if we sum up the partial charges of the first four alkyl groups we find a charge of 0.19|e|, 0.16|e| and 0.11|e| respectively for MK, CHELPG and CHELP method. The sum of the partial charges on Met5, Met6 and Met7 was close to 0.3|e| for all the methods whereas the sum of the last four alkyl groups lead to a charge of $0|e|$. Consequently, even if the partial charges of the alkyl group seemed wrong the distribution of the charge along the tail was consistent with the electrostatic potential.

This delocalization is also visible on Fig. 3 representing the distribution of the partial charge evaluated with the APT and NPA methods. The evolution of the charge along the tail was very similar whereas the methods are completely different from a technical point of view. In 
both cases we had a low partial charge on Met1 and then a greater charge on Met2 followed by a monotonous decrease of the partial charges until Met8. As in Fig. 2, we can see an odd even effect but only on the last four methyl groups. The sums of the partial charges on the last four alkyl groups were 0.02|e| and 0.01|e| respectively for APT and NPA. This result is in agreement with the positive electrostatic potential visible at the end of the tail in Fig. 1.

As expected the partial charges given in commercial force fields did not take into account the distribution of the positive charge on the tail, Fig. 4. The semiempirical method Gasteiger gave a positive charge delocalized on the first two alkyl groups whereas Qeq delocalized more than $60 \%$ of the charge all along the tail, the last alkyl group having a charge higher than $0.10|e|$. Consequently, from these results, the Qeq method did not seem appropriate for the evaluation of the atomic partial charge in the dodecyltrimethylammonium.

With regard to the results on a whole it is obvious that all the tested methods provided different distributions of the partial charges. However, it is complicated to conclude which method is the best due to the difficulty in finding the quality criteria. Nevertheless, these partial charges are intended to be used as input parameters in atomistic simulations. Consequently, it would be interesting to see if the discrepancies induced by the different models of atomic partial charges are within the range for statistical error generated by molecular dynamic simulations.

\section{Conclusions}

The electrostatic potential of dodecyltrimethylammonium ion was evaluated at different level for various theories. Then, the influence of the methods for deriving atomic charges from the electrostatic potential was analyzed. The results were compared to other quantum techniques, the natural population analysis (NPA), the Cioslowki's atomic polar tensor (APT) and semi empirical methods. From the electrostatic potential, the molecule can clearly be divided into three parts in function of the values ranging from 0 to $127 \mathrm{kcal} \mathrm{mol}^{-1}$. The partial charges evaluated with the NPA and APT methods represent pretty well the monotonous decrease of the electrostatic potential along the tail. The same is true for the methods based on the fitting of the electrostatic potential giving some unrealistic negative partial charges along the tail. It is clear from the results that the different methods provide different estimations of the atomic 
charges. However, further investigations are now necessary to assess the influence of these different distributions of charge on the results obtained with atomistic simulation. 


\section{References}

1. Welton T (1999) Chem Rev 99:2071-2083

2. Holmberg K (2003) J Colloid Interf Sci 274:355-364

3. Holmberg K (2003) J Colloid Interf Sci 274:355-364

4. Rajagopalan R (2001) Curr Opin Colloid Interface Sci 6:357-365

5. Li YM, X GY, Chen YJ, Luan YX, Yuan SL (2006) Comp Mat Sci 36:386-396

6. Heinz H, Suter UW (2004) J Phys Chem B 108:18341-18352

7. Heinz H, Vaia RA, Farmer BL (2006) J. Chem. Phy. 124:2247131-2247139

8. He H, Galy J, Gerard JF (2005) J Phys Chem B 109:13301-13306

9. Minisini B, Tsobnang F (2005) Composites Part A 36:531-537

10. Yuan S, Ma L, Zhang X, Zheng L Chen Y, Xu G (2006) Colloids Surf A 289:1-9

11. Yuan S, Chen Y, Xu G (2006) Colloids Surf A 280:108-115

12. Piotrovskaya, EM, Vanin AA, Smirnova NA (2006) Mol Phys 104:3645-3651

13. Martynkova GS, Valaskova M, Capkova P, Matejka V (2007) J Colloid Interf Sci $313: 281-287$

14. Pospisil M, Capkova P, Merinska D, Malac Z, Simonik J (2001) J Colloid Interf Sci 236:127-131

15. Capkova P, Pospisil M, Weiss Z (2003) J Mol Model 9:195-205

16. Gardebien F, Gaudel-Siri A, Bredas JL, Lazzaroni R (2004) J Phys Chem B 108:1067810686

17. Gardebien F, Bredas JL, Lazzaroni R (2005) J Phys Chem B 109:12287-12296

18. Jang SS, Goddard III WA (2006) J Phys Chem B 110:7992-8001

19. Zeng QH, Yu AB, Lu GQ, Standish RK (2003) Chem Mater 15:4732-4738

20. Zeng QH, Yu AB, Lu GQ Standish RK (2004) J Phys Chem B 108:10025-10033

21. Paul DR, Zeng QH, Yu AB, Lu GQ (2005) J Colloid Interf Sci 292:462-468

22. Tanaka G, Goettler L (2002) Polymer 43:541-553

23. Zeng QH, Yu A, Lu G (2005) Nanotechnology 16:2757-2763

24. Jorgensen WL, Gao J (1986) J Phys Chem 90:2174-2182

25. Bandyopadhyay S, Shelley JC, Tarek M, Moore PB, Klein ML (1998) J Phys Chem B 102:6318-6322

26. Tarek M, Tobias DJ, Klein ML (1995) J Phys Chem 99:1393-1402

27. Adolf DB, Tideslsey DJ, Pinches MRS, Kingdon JB, Madden T, Clark A (1995) Langmuir 11:237-246 
28. Shah K, Chiu P, Jain M, J Fortes, B Moudgil, Sinnott S (2005) Langmuir 21:5337-5342

29. Kong YC, Tildesley DJ, Alejandre J (1997) Mol Phys 92:7-18

30. Böcker J, Schlenkrich M, Bopp P, Brickmann J (1992) J Phys Chem 96:9915-9922

31. Dos Santos DJVA, Gomes JANF (2004) Progr Colloid Polym Sci 126:68-73

32. Böcker J, Brickmann J, Bopp P (1994) J Phys Chem 98:712-717

33. Zanuy D, Casanovas J, Aleman C (2004) Chem Phys 305:85-93

34. Zanuy D, Aleman C (2003) Langmuir 19:3987-3995

35. Zanuy D, Aleman C, Munoz-Guerra S (2002) Biopolymers 63:151-162

36. Meleshyn A, Bunnenberg C (2006) J Phys Chem B 110: 2271-2277

37. Teppen BJ, Rasmussen K, Bertsch PM, Miller DM, Schafer L (1997) J Phys Chem B 101:1579-1587

38. Huibers PDT (1999) Langmuir 15:7546-7550

39. Frisch MJ, Trucks GW, Schlegel HB, Scuseria GE, Robb MA, Cheeseman JR, Zakrzewski VG, Montgomery JA Jr, , Stratmann RE, Burant JC, Dapprich S, Millam JM, Daniels AD, Kudin KN, Strain MC, Farkas O, Tomasi J, Barone V, Cossi M, Cammi R, Mennucci B, Pomelli C, Adamo C, Clifford S, Ochterski J, Petersson GA, Ayala PY, Cui Q, Morokuma K, Malick DK, Rabuck AD, Raghavachari K, Foresman JB, Cioslowski J, Ortiz JV, Baboul AG, Stefanov BB, Liu G, Liashenko A, Piskorz P, Komaromi I, Gomperts R, Martin RL, Fox DJ, Keith T, Al-Laham MA, Peng CY, Nanayakkara A, Gonzalez C, Challacombe M, Gill PMW, Johnson B, Chen W, Wong MW, Andres JL, Gonzalez C, Head-Gordon M, Replogle ES, and Pople JA (1998) Gaussian 98, Revision A7. Gaussian Inc, Pittsburgh, PA

40. Peng C, Ayala PY, Schlegel HB, Frisch MJ (1996) J Comput Chem 17:49-56

41. Roothaan CCJ (1951) Rev Mod Phys 23:69-89

42. Moller C, Plesset MS (1934) Phys Rev B 46:618-622

43. Vosko SH, Wilk L, Nusair M (1980) Can J Phys 58:1200-1211

44. Perdew JP, Buke K, Ernerhof M (1996) Phys Rev Lett 77:3865-3868

45. Becke AD (1993) J Chem Phys 98:5648-5652

46. Lee C, Yang W, Parr RG (1988) Phys Rev B 37:785-789

47. Frisch MJ, Trucks GW, Schlegel HB, Scuseria GE, Robb MA, Cheeseman JR, Montgomery Jr JA, Vreven T Kudin KN, Burant JC, Millam JM, Iyengar SS, Tomasi J, Barone V, Mennucci B, Cossi M, Scalmani G, Rega N, Petersson, GA, Nakatsuji H, Hada M, Ehara M, Toyota K, Fukuda R, Hasegawa J, Ishida M, Nakajima T, Honda Y, Kitao O, Nakai H, Klene M, Li X, Knox JE, Hratchian HP, Cross JB, Bakken V, Adamo 
C, Jaramillo, J, Gomperts R, Stratmann RE, Yazyev O, Austin A J, Cammi R, Pomelli C, Ochterski JW, Ayala PY, Morokuma K, Voth GA, Salvador P, Dannenberg JJ, Zakrzewski VG, Dapprich S, Daniels AD, Strain MC, Farkas O, Malick DK, Rabuck AD, Raghavachari K, Foresman JB, Ortiz, JV, Cui Q, Baboul AG, Clifford S, Cioslowski J, Stefanov BB, Liu G, Liashenko A, Piskorz P, Komaromi I, Martin RL, Fox DJ, Keith T, Al-Laham MA, Peng CY, Nanayakkara A, Challacombe M, Gill PMW, Johnson B, Chen W, Wong MW, Gonzalez C, and Pople JA (2004) Gaussian 03, Revision C.02. Gaussian Inc, Wallingford CT

48. Chirlian LE, Francl MM (1987) J Comput Chem 8:894-905

49. Breneman CM, Wiberg KB (1990) J Comput Chem 11:361-373

50. Besler BH, Merz KM, Kollman PA (1990) J Comput Chem 11:431-439

51. Singh UC, Kollman PA (1984) J Comput Chem 5:129-145

52. Reed AE, Weinstock RB, Weinhold F (1985) J Chem Phys 83:735-746

53. Reed AE, Curtiss E, Weinstock RB (1988) D Chem Rev 88:899-926

54. Cioslowski J (1989) Phys Rev Lett 62:1469-1471

55. Cioslowski J (1989) J Am Chem Soc 111:8333-8336

56. Accelrys Inc, San Diego, 2004

57. Rappe AK, Goddard WA (1991) J Phys Chem 95:3358-3363

58. Gasteiger J, Marsili M (1980) Tetrahedron 36:3219-3228

59. Masamura M (2000) Structural Chemistry 11:41-45

60. Sigfridsson E, Ryde U (1998) J Comput Chem 19:377-395

61. Pople JA, Gordon M (1967) J Am Chem Soc 89:4253-4261

62. Politzer P, Whittenburg SLS, Wärnheim T (1982) J Phys Chem 86:2609-2613

63. Weinstein H, Maayani S, Srebenik S, Cohen S, Sokolovsky M (1973) Mol Pharmacol 9, 820-834 
1 Table 1 Atomic partial charges calculated in the framework of the density functional theory

\begin{tabular}{|c|c|c|c|c|c|c|c|c|c|c|c|c|c|c|}
\hline & & \multicolumn{4}{|c|}{ LDA-6-31++G(d,p) } & \multicolumn{4}{|c|}{ PBE-6-31++G(d,p) } & \multicolumn{5}{|c|}{ B3LYP-6-31++G(d,p) } \\
\hline & & MK & CHELP & CHELPG & NPA & MK & CHELP & CHELPG & NPA & MK & CHELP & CHELPG & NPA & APT \\
\hline $\mathrm{N}$ & $\mathrm{N}$ & 0.05 & 0.23 & 0.14 & -0.29 & 0.10 & 0.26 & 0.17 & -0.31 & 0.11 & 0.27 & 0.18 & -0.33 & -0.43 \\
\hline$C_{1}$ & $C_{1}$ & -0.41 & -0.09 & -0.28 & -0.54 & -0.38 & -0.07 & -0.25 & -0.48 & -0.35 & -0.05 & -0.22 & -0.45 & 0.17 \\
\hline $\mathrm{H}_{1 \mathrm{a}}$ & $\mathrm{H}_{1 \mathrm{a}}$ & 0.21 & 0.08 & 0.16 & 0.29 & 0.19 & 0.07 & 0.14 & 0.27 & 0.18 & 0.06 & 0.13 & 0.26 & 0.04 \\
\hline $\mathrm{H}_{1 \mathrm{~b}}$ & $\mathrm{H}_{1 \mathrm{~b}}$ & 0.23 & 0.10 & 0.17 & 0.29 & 0.21 & 0.09 & 0.16 & 0.27 & 0.20 & 0.08 & 0.15 & 0.26 & 0.05 \\
\hline $\mathrm{H}_{1 \mathrm{c}}$ & $\mathrm{H}_{1 \mathrm{c}}$ & 0.20 & 0.09 & 0.16 & 0.29 & 0.19 & 0.08 & 0.14 & 0.27 & 0.18 & 0.08 & 0.13 & 0.26 & 0.05 \\
\hline$C_{2}$ & $C_{2}$ & -0.41 & -0.08 & -0.28 & -0.54 & -0.38 & -0.06 & -0.25 & -0.48 & -0.35 & -0.05 & -0.22 & -0.45 & 0.17 \\
\hline $\mathrm{H}_{2 \mathrm{a}}$ & $\mathrm{H}_{2 \mathrm{a}}$ & 0.23 & 0.10 & 0.17 & 0.29 & 0.21 & 0.09 & 0.16 & 0.27 & 0.20 & 0.08 & 0.15 & 0.26 & 0.05 \\
\hline $\mathrm{H}_{2 \mathrm{~b}}$ & $\mathrm{H}_{2 \mathrm{~b}}$ & 0.21 & 0.08 & 0.16 & 0.29 & 0.19 & 0.07 & 0.14 & 0.27 & 0.18 & 0.06 & 0.13 & 0.26 & 0.04 \\
\hline $\mathrm{H}_{2 \mathrm{c}}$ & $\mathrm{H}_{2 \mathrm{c}}$ & 0.21 & 0.09 & 0.16 & 0.29 & 0.19 & 0.08 & 0.14 & 0.27 & 0.18 & 0.08 & 0.13 & 0.26 & 0.05 \\
\hline$C_{3}$ & $C_{3}$ & -0.53 & -0.34 & -0.32 & -0.54 & -0.48 & -0.30 & -0.28 & -0.48 & -0.45 & -0.28 & -0.25 & -0.45 & 0.19 \\
\hline $\mathrm{H}_{3 \mathrm{a}}$ & $\mathrm{H}_{3 \mathrm{a}}$ & 0.24 & 0.15 & 0.17 & 0.29 & 0.22 & 0.13 & 0.15 & 0.27 & 0.21 & 0.12 & 0.14 & 0.26 & 0.05 \\
\hline $\mathrm{H}_{3 \mathrm{~b}}$ & $\mathrm{H}_{3 b}$ & 0.24 & 0.15 & 0.17 & 0.29 & 0.22 & 0.13 & 0.15 & 0.27 & 0.21 & 0.12 & 0.14 & 0.26 & 0.05 \\
\hline $\mathrm{H}_{3 \mathrm{c}}$ & $\mathrm{H}_{3 \mathrm{c}}$ & 0.25 & 0.18 & 0.17 & 0.29 & 0.23 & 0.16 & 0.16 & 0.27 & 0.22 & 0.15 & 0.15 & 0.26 & 0.04 \\
\hline$C_{\alpha}$ & $C$ & -0.24 & 0.08 & -0.19 & -0.30 & -0.21 & 0.09 & -0.16 & -0.26 & -0.19 & 0.10 & -0.15 & -0.23 & 0.34 \\
\hline $\mathrm{H}_{\alpha}$ & $\mathrm{H}$ & 0.16 & 0.02 & 0.12 & 0.28 & 0.14 & 0.02 & 0.11 & 0.27 & 0.14 & 0.01 & 0.10 & 0.26 & 0.00 \\
\hline $\mathrm{H}_{\alpha}$ & $\mathrm{H}$ & 0.16 & 0.02 & 0.12 & 0.28 & 0.14 & 0.02 & 0.11 & 0.27 & 0.14 & 0.01 & 0.10 & 0.26 & 0.00 \\
\hline$C_{t 1}$ & $C$ & 0.04 & 0.18 & 0.07 & -0.54 & 0.05 & 0.19 & 0.08 & -0.50 & 0.06 & 0.20 & 0.09 & -0.48 & 0.00 \\
\hline $\mathrm{H}_{t 1}$ & $\mathrm{H}$ & 0.05 & -0.06 & 0.02 & 0.27 & 0.04 & -0.06 & 0.01 & 0.25 & 0.03 & -0.07 & 0.01 & 0.24 & -0.01 \\
\hline $\mathrm{H}_{t l}$ & $\mathrm{H}$ & 0.05 & -0.06 & 0.02 & 0.27 & 0.04 & -0.06 & 0.01 & 0.25 & 0.03 & -0.07 & 0.01 & 0.24 & -0.01 \\
\hline$C_{t 2}$ & $C$ & -0.08 & -0.08 & 0.00 & -0.51 & -0.05 & -0.05 & 0.03 & -0.47 & -0.04 & -0.04 & 0.04 & -0.45 & 0.13 \\
\hline $\mathrm{H}_{t 2}$ & $\mathrm{H}$ & 0.05 & 0.01 & 0.02 & 0.26 & 0.04 & 0.00 & 0.01 & 0.25 & 0.03 & -0.01 & 0.00 & 0.23 & -0.03 \\
\hline $\mathrm{H}_{t 2}$ & $\mathrm{H}$ & 0.05 & 0.01 & 0.02 & 0.26 & 0.03 & 0.00 & 0.01 & 0.25 & 0.03 & -0.01 & 0.00 & 0.23 & -0.03 \\
\hline$C_{t 3}$ & $C$ & -0.06 & 0.19 & -0.07 & -0.51 & -0.04 & 0.20 & -0.05 & -0.47 & -0.02 & 0.22 & -0.03 & -0.45 & 0.11 \\
\hline $\mathrm{H}_{t 4}$ & $\mathrm{H}$ & 0.03 & -0.04 & 0.02 & 0.26 & 0.02 & -0.05 & 0.01 & 0.24 & 0.01 & -0.05 & 0.00 & 0.23 & -0.04 \\
\hline $\mathrm{H}_{t 4}$ & $\mathrm{H}$ & 0.03 & -0.04 & 0.02 & 0.26 & 0.02 & -0.05 & 0.01 & 0.24 & 0.01 & -0.05 & 0.01 & 0.23 & -0.04 \\
\hline$C_{t 15}$ & $C$ & 0.06 & 0.07 & 0.04 & -0.51 & 0.08 & 0.09 & 0.06 & -0.47 & 0.09 & 0.10 & 0.07 & -0.45 & 0.10 \\
\hline $\mathrm{H}_{t 5}$ & $\mathrm{H}$ & 0.00 & -0.04 & 0.00 & 0.26 & -0.01 & -0.05 & -0.01 & 0.24 & -0.02 & -0.06 & -0.02 & 0.23 & -0.04 \\
\hline $\mathrm{H}_{t 5}$ & $\mathrm{H}$ & 0.00 & -0.04 & 0.00 & 0.26 & -0.01 & -0.05 & -0.01 & 0.24 & -0.02 & -0.06 & -0.02 & 0.23 & -0.04 \\
\hline$C_{t 6}$ & $C$ & -0.05 & 0.05 & 0.02 & -0.51 & -0.03 & 0.07 & 0.04 & -0.47 & -0.01 & 0.09 & 0.06 & -0.44 & 0.10 \\
\hline $\mathrm{H}_{t 6}$ & $\mathrm{H}$ & 0.02 & -0.05 & 0.00 & 0.26 & 0.00 & -0.06 & -0.01 & 0.24 & 0.00 & -0.06 & -0.02 & 0.23 & -0.05 \\
\hline $\mathrm{H}_{t 6}$ & $\mathrm{H}$ & 0.02 & -0.05 & 0.00 & 0.26 & 0.00 & -0.06 & -0.01 & 0.24 & 0.00 & -0.06 & -0.02 & 0.23 & -0.05 \\
\hline
\end{tabular}




\begin{tabular}{|c|c|c|c|c|c|c|c|c|c|c|c|c|c|c|}
\hline$C_{t 7}$ & $C$ & -0.01 & 0.24 & 0.00 & -0.51 & 0.01 & 0.25 & 0.02 & -0.47 & 0.02 & 0.27 & 0.04 & -0.44 & 0.11 \\
\hline $\mathrm{H}_{t 7}$ & $\mathrm{H}$ & 0.01 & -0.07 & 0.00 & 0.26 & 0.00 & -0.08 & -0.01 & 0.24 & -0.01 & -0.09 & -0.02 & 0.22 & -0.05 \\
\hline $\mathrm{H}_{t 7}$ & $\mathrm{H}$ & 0.01 & -0.07 & 0.00 & 0.26 & 0.00 & -0.08 & -0.01 & 0.24 & -0.01 & -0.09 & -0.02 & 0.22 & -0.05 \\
\hline$C_{t 8}$ & $C$ & 0.08 & 0.06 & 0.07 & -0.51 & 0.09 & 0.08 & 0.09 & -0.47 & 0.10 & 0.09 & 0.10 & -0.44 & 0.10 \\
\hline $\mathrm{H}_{t 8}$ & $\mathrm{H}$ & -0.01 & -0.04 & -0.02 & 0.25 & -0.02 & -0.05 & -0.03 & 0.24 & -0.03 & -0.06 & -0.03 & 0.22 & -0.05 \\
\hline $\mathrm{H}_{t 8}$ & $\mathrm{H}$ & -0.01 & -0.04 & -0.02 & 0.25 & -0.02 & -0.05 & -0.03 & 0.24 & -0.03 & -0.06 & -0.03 & 0.22 & -0.05 \\
\hline$C_{t 9}$ & $C$ & -0.09 & 0.01 & -0.04 & -0.51 & -0.06 & 0.04 & -0.02 & -0.47 & -0.05 & 0.06 & 0.00 & -0.44 & 0.11 \\
\hline $\mathrm{H}_{t 9}$ & $\mathrm{H}$ & 0.02 & -0.04 & 0.00 & 0.25 & 0.01 & -0.05 & -0.01 & 0.24 & 0.00 & -0.05 & -0.02 & 0.22 & -0.05 \\
\hline $\mathrm{H}_{t 9}$ & $\mathrm{H}$ & 0.02 & -0.04 & 0.00 & 0.25 & 0.01 & -0.05 & -0.01 & 0.24 & 0.00 & -0.05 & -0.02 & 0.22 & -0.05 \\
\hline$C_{t 10}$ & $C$ & -0.03 & 0.19 & -0.01 & -0.51 & -0.01 & 0.21 & 0.01 & -0.47 & 0.01 & 0.22 & 0.03 & -0.45 & 0.10 \\
\hline $\mathrm{H}_{t 10}$ & $\mathrm{H}$ & 0.01 & -0.06 & 0.00 & 0.25 & 0.00 & -0.07 & -0.01 & 0.24 & -0.01 & -0.08 & -0.02 & 0.22 & -0.05 \\
\hline $\mathrm{H}_{t 10}$ & $\mathrm{H}$ & 0.01 & -0.06 & 0.00 & 0.25 & 0.00 & -0.07 & -0.01 & 0.24 & -0.01 & -0.08 & -0.02 & 0.22 & -0.05 \\
\hline$C_{t 11}$ & $C$ & 0.16 & 0.18 & 0.16 & -0.51 & 0.18 & 0.19 & 0.17 & -0.48 & 0.19 & 0.20 & 0.18 & -0.45 & 0.13 \\
\hline $\mathrm{H}_{t 11}$ & $\mathrm{H}$ & -0.02 & -0.06 & -0.02 & 0.25 & -0.03 & -0.07 & -0.03 & 0.24 & -0.04 & -0.08 & -0.04 & 0.22 & -0.05 \\
\hline $\mathrm{H}_{t 11}$ & $\mathrm{H}$ & -0.02 & -0.06 & -0.02 & 0.25 & -0.03 & -0.07 & -0.03 & 0.24 & -0.04 & -0.08 & -0.04 & 0.22 & -0.05 \\
\hline$C_{t 12}$ & $C$ & -0.32 & -0.12 & -0.25 & -0.75 & -0.27 & -0.08 & -0.20 & -0.69 & -0.25 & -0.06 & -0.18 & -0.66 & 0.08 \\
\hline $\mathrm{H}_{t 12}$ & $\mathrm{H}$ & 0.08 & 0.01 & 0.06 & 0.25 & 0.06 & 0.00 & 0.04 & 0.23 & 0.05 & -0.01 & 0.03 & 0.22 & -0.03 \\
\hline $\mathrm{H}_{t 12}$ & $\mathrm{H}$ & 0.08 & 0.01 & 0.06 & 0.25 & 0.06 & 0.00 & 0.04 & 0.23 & 0.05 & -0.01 & 0.03 & 0.22 & -0.03 \\
\hline $\mathrm{H}_{t 12}$ & $\mathrm{H}$ & 0.09 & 0.05 & 0.07 & 0.26 & 0.07 & 0.03 & 0.05 & 0.24 & 0.06 & 0.02 & 0.04 & 0.23 & -0.04 \\
\hline
\end{tabular}


4 Table 2 Atomic partial charges calculated at the Hartree Fock and post Hartree Fock level

5 of theory, semi empirical level and given by commercial force field

6

\begin{tabular}{|c|c|c|c|c|c|c|c|c|c|c|c|}
\hline & \multicolumn{4}{|c|}{ HF-6-31++G(d,p) } & \multicolumn{4}{|c|}{ MP2-6-31++G(d,p) } & \multicolumn{2}{|c|}{ Semi empirical } & \multirow{2}{*}{$\begin{array}{l}\text { Force field } \\
\text { COMPASS }\end{array}$} \\
\hline & MK & CHELP & CHELPG & NPA & MK & CHELP & CHELPG & NPA & Gasteiger & Qeq & \\
\hline $\mathrm{N}$ & 0.15 & 0.32 & 0.22 & -0.41 & 0,15 & 0,32 & 0,22 & $-0,41$ & 0.14 & -0.40 & -0.628 \\
\hline$C_{1}$ & -0.38 & -0.08 & -0.25 & -0.37 & $-0,38$ & $-0,08$ & $-0,25$ & $-0,37$ & 0.02 & -0.25 & 0.248 \\
\hline $\mathrm{H}_{1 \mathrm{a}}$ & 0.19 & 0.07 & 0.14 & 0.24 & 0,19 & 0,07 & 0,14 & 0,24 & 0.06 & 0.15 & 0.053 \\
\hline $\mathrm{H}_{1 \mathrm{~b}}$ & 0.21 & 0.09 & 0.15 & 0.24 & 0,21 & 0,09 & 0,15 & 0,24 & 0.06 & 0.15 & 0.053 \\
\hline $\mathrm{H}_{1 \mathrm{c}}$ & 0.19 & 0.08 & 0.14 & 0.24 & 0,19 & 0,08 & 0,14 & 0,24 & 0.06 & 0.15 & 0.053 \\
\hline$C_{2}$ & -0.38 & -0.08 & -0.25 & -0.37 & $-0,38$ & $-0,08$ & $-0,25$ & $-0,37$ & 0.02 & -0.25 & 0.248 \\
\hline $\mathrm{H}_{2 \mathrm{a}}$ & 0.21 & 0.09 & 0.16 & 0.24 & 0,21 & 0,09 & 0,15 & 0,24 & 0.06 & 0.16 & 0.053 \\
\hline $\mathrm{H}_{2 \mathrm{~b}}$ & 0.19 & 0.07 & 0.14 & 0.24 & 0,19 & 0,07 & 0,14 & 0,24 & 0.06 & 0.15 & 0.053 \\
\hline $\mathrm{H}_{2 \mathrm{c}}$ & 0.19 & 0.08 & 0.14 & 0.24 & 0,19 & 0,08 & 0,14 & 0,24 & 0.06 & 0.15 & 0.053 \\
\hline$C_{3}$ & -0.51 & -0.33 & -0.28 & -0.37 & $-0,51$ & $-0,33$ & $-0,28$ & $-0,37$ & 0.02 & -0.27 & 0.248 \\
\hline $\mathrm{H}_{3 \mathrm{a}}$ & 0.22 & 0.13 & 0.15 & 0.24 & 0,22 & 0,13 & 0,15 & 0,24 & 0.06 & 0.15 & 0.053 \\
\hline $\mathrm{H}_{3 \mathrm{~b}}$ & 0.22 & 0.13 & 0.15 & 0.24 & 0,22 & 0,13 & 0,15 & 0,24 & 0.06 & 0.16 & 0.053 \\
\hline $\mathrm{H}_{3 \mathrm{c}}$ & 0.23 & 0.16 & 0.16 & 0.24 & 0,23 & 0,16 & 0,16 & 0,24 & 0.06 & 0.16 & 0.053 \\
\hline$C_{\alpha}$ & -0.23 & 0.11 & -0.17 & -0.17 & $-0,23$ & 0,11 & $-0,17$ & $-0,17$ & 0.04 & -0.13 & 0.301 \\
\hline $\mathrm{H}_{\alpha}$ & 0.15 & 0.01 & 0.11 & 0.24 & 0,15 & 0,01 & 0,11 & 0,24 & 0.07 & 0.16 & 0.053 \\
\hline $\mathrm{H}_{\alpha}$ & 0.15 & 0.01 & 0.11 & 0.24 & 0,15 & 0,01 & 0,11 & 0,24 & 0.07 & 0.16 & 0.053 \\
\hline$C_{t l}$ & 0.07 & 0.20 & 0.10 & -0.44 & 0,07 & 0,20 & 0,10 & $-0,44$ & -0.02 & -0.28 & -0.106 \\
\hline $\mathrm{H}_{t l}$ & 0.03 & -0.07 & 0.00 & 0.22 & 0,03 & $-0,07$ & 0,00 & 0,22 & 0.03 & 0.16 & 0.053 \\
\hline $\mathrm{H}_{t l}$ & 0.03 & -0.07 & 0.00 & 0.22 & 0,03 & $-0,07$ & 0,00 & 0,22 & 0.03 & 0.16 & 0.053 \\
\hline$C_{t 2}$ & -0.05 & -0.05 & 0.04 & -0.41 & $-0,05$ & $-0,05$ & 0,04 & $-0,41$ & -0.05 & -0.31 & -0.106 \\
\hline $\mathrm{H}_{t 2}$ & 0.03 & 0.00 & 0.00 & 0.22 & 0,03 & 0,00 & 0,00 & 0,22 & 0.03 & 0.17 & 0.053 \\
\hline $\mathrm{H}_{t 2}$ & 0.03 & 0.00 & 0.00 & 0.22 & 0,03 & 0,00 & 0,00 & 0,22 & 0.03 & 0.17 & 0.053 \\
\hline$C_{t 3}$ & -0.03 & 0.21 & -0.05 & -0.41 & $-0,03$ & 0,21 & $-0,05$ & $-0,41$ & -0.05 & -0.29 & -0.106 \\
\hline $\mathrm{H}_{t 4}$ & 0.01 & -0.05 & 0.01 & 0.21 & 0,01 & $-0,05$ & 0,01 & 0,21 & 0.03 & 0.17 & 0.053 \\
\hline $\mathrm{H}_{t 4}$ & 0.01 & -0.05 & 0.01 & 0.21 & 0,01 & $-0,05$ & 0,01 & 0,21 & 0.03 & 0.17 & 0.053 \\
\hline$C_{t 15}$ & 0.09 & 0.10 & 0.07 & -0.41 & 0,09 & 0,10 & 0,07 & $-0,41$ & -0.05 & -0.29 & -0.106 \\
\hline $\mathrm{H}_{t 5}$ & -0.02 & -0.06 & -0.02 & 0.21 & $-0,02$ & $-0,06$ & $-0,02$ & 0,21 & 0.03 & 0.17 & 0.053 \\
\hline $\mathrm{H}_{t 5}$ & -0.02 & -0.06 & -0.02 & 0.21 & $-0,02$ & $-0,06$ & $-0,02$ & 0,21 & 0.03 & 0.17 & 0.053 \\
\hline$C_{t 6}$ & -0.02 & 0.07 & 0.05 & -0.41 & $-0,02$ & 0,07 & 0,05 & $-0,41$ & -0.05 & -0.30 & -0.106 \\
\hline $\mathrm{H}_{t 6}$ & 0.00 & -0.06 & -0.02 & 0.21 & 0,00 & $-0,06$ & $-0,02$ & 0,21 & 0.03 & 0.17 & 0.053 \\
\hline $\mathrm{H}_{t 6}$ & 0.00 & -0.06 & -0.02 & 0.21 & 0,00 & $-0,06$ & $-0,02$ & 0,21 & 0.03 & 0.17 & 0.053 \\
\hline$C_{t 7}$ & 0.02 & 0.26 & 0.03 & -0.41 & 0,02 & 0,26 & 0,03 & $-0,41$ & -0.05 & -0.29 & -0.106 \\
\hline $\mathrm{H}_{t 7}$ & -0.01 & -0.08 & -0.02 & 0.21 & $-0,01$ & $-0,08$ & $-0,02$ & 0,21 & 0.03 & 0.17 & 0.053 \\
\hline $\mathrm{H}_{t 7}$ & -0.01 & -0.08 & -0.02 & 0.21 & $-0,01$ & $-0,08$ & $-0,02$ & 0,21 & 0.03 & 0.17 & 0.053 \\
\hline$C_{t 8}$ & 0.10 & 0.09 & 0.10 & -0.41 & 0,10 & 0,09 & 0,10 & $-0,41$ & -0.05 & -0.30 & -0.106 \\
\hline $\mathrm{H}_{t 8}$ & -0.03 & -0.05 & -0.03 & 0.20 & $-0,03$ & $-0,05$ & $-0,03$ & 0,20 & 0.03 & 0.17 & 0.053 \\
\hline $\mathrm{H}_{t 8}$ & -0.03 & -0.05 & -0.03 & 0.20 & $-0,02$ & $-0,05$ & $-0,03$ & 0,20 & 0.03 & 0.17 & 0.053 \\
\hline$C_{t 9}$ & -0.07 & 0.03 & -0.02 & -0.41 & $-0,06$ & 0,03 & $-0,02$ & $-0,41$ & -0.05 & -0.30 & -0.106 \\
\hline $\mathrm{H}_{t 9}$ & 0.00 & -0.05 & -0.01 & 0.20 & 0,00 & $-0,05$ & $-0,01$ & 0,20 & 0.03 & 0.17 & 0.053 \\
\hline $\mathrm{H}_{t 9}$ & 0.00 & -0.05 & -0.01 & 0.20 & 0,00 & $-0,05$ & $-0,01$ & 0,20 & 0.03 & 0.17 & 0.053 \\
\hline$C_{t 10}$ & 0.00 & 0.22 & 0.03 & -0.41 & 0,00 & 0,22 & 0,03 & $-0,41$ & -0.05 & -0.28 & -0.106 \\
\hline $\mathrm{H}_{t 10}$ & 0.00 & -0.07 & -0.01 & 0.20 & 0,00 & $-0,07$ & $-0,01$ & 0,20 & 0.03 & 0.18 & 0.053 \\
\hline $\mathrm{H}_{t 10}$ & 0.00 & -0.07 & -0.01 & 0.20 & 0,00 & $-0,07$ & $-0,01$ & 0,20 & 0.03 & 0.18 & 0.053 \\
\hline$C_{t 11}$ & 0.19 & 0.20 & 0.19 & -0.42 & 0,19 & 0,20 & 0,18 & $-0,42$ & -0.06 & -0.30 & -0.106 \\
\hline $\mathrm{H}_{t 11}$ & -0.03 & -0.07 & -0.04 & 0.20 & $-0,03$ & $-0,07$ & $-0,04$ & 0,20 & 0.03 & 0.18 & 0.053 \\
\hline $\mathrm{H}_{t 11}$ & -0.03 & -0.07 & -0.04 & 0.20 & $-0,03$ & $-0,07$ & $-0,04$ & 0,20 & 0.03 & 0.18 & 0.053 \\
\hline$C_{t 12}$ & -0.28 & -0.09 & -0.21 & -0.60 & $-0,28$ & $-0,09$ & $-0,21$ & $-0,60$ & -0.07 & -0.41 & -0.159 \\
\hline $\mathrm{H}_{t 12}$ & 0.06 & -0.01 & 0.04 & 0.20 & 0,06 & $-0,01$ & 0,04 & 0,20 & 0.02 & 0.17 & 0.053 \\
\hline $\mathrm{H}_{t 12}$ & 0.06 & -0.01 & 0.04 & 0.20 & 0,06 & $-0,01$ & 0,04 & 0,20 & 0.02 & 0.17 & 0.053 \\
\hline $\mathrm{H}_{t 12}$ & 0.07 & 0.03 & 0.05 & 0.21 & 0,07 & 0,03 & 0,05 & 0,21 & 0.02 & 0.17 & 0.053 \\
\hline
\end{tabular}




\section{$8 \quad$ Figure captions}

9 Fig. 1 Mapping of the electrostatic potential onto the electron density surface $(0.002$ e/bohr ${ }^{3}$ ) evaluated at B3LYP//6-31G++(d,p) level, blue represents more electrophilic regions and red less electrophilic regions

12

13 Fig. 2 Distribution of the derived partial charges from electrostatic potential along the alkyl tail. Met $\mathrm{X}_{\mathrm{X}}$ stands for the $\mathrm{X}^{\text {th }}$ methylene group composed of $\mathrm{C}_{\mathrm{tX}}$ and the two 16

Fig. 3 Distribution of partial charges estimated from the natural population analysis 18 (NPA) and the Cioslowki's atomic polar tensor (APT) along the alkyl tail

Fig. 4 Distribution of partial charges estimated from semiempirical method Qeq and Gasteiger and available in COMPASS force field 
Click here to download high resolution image
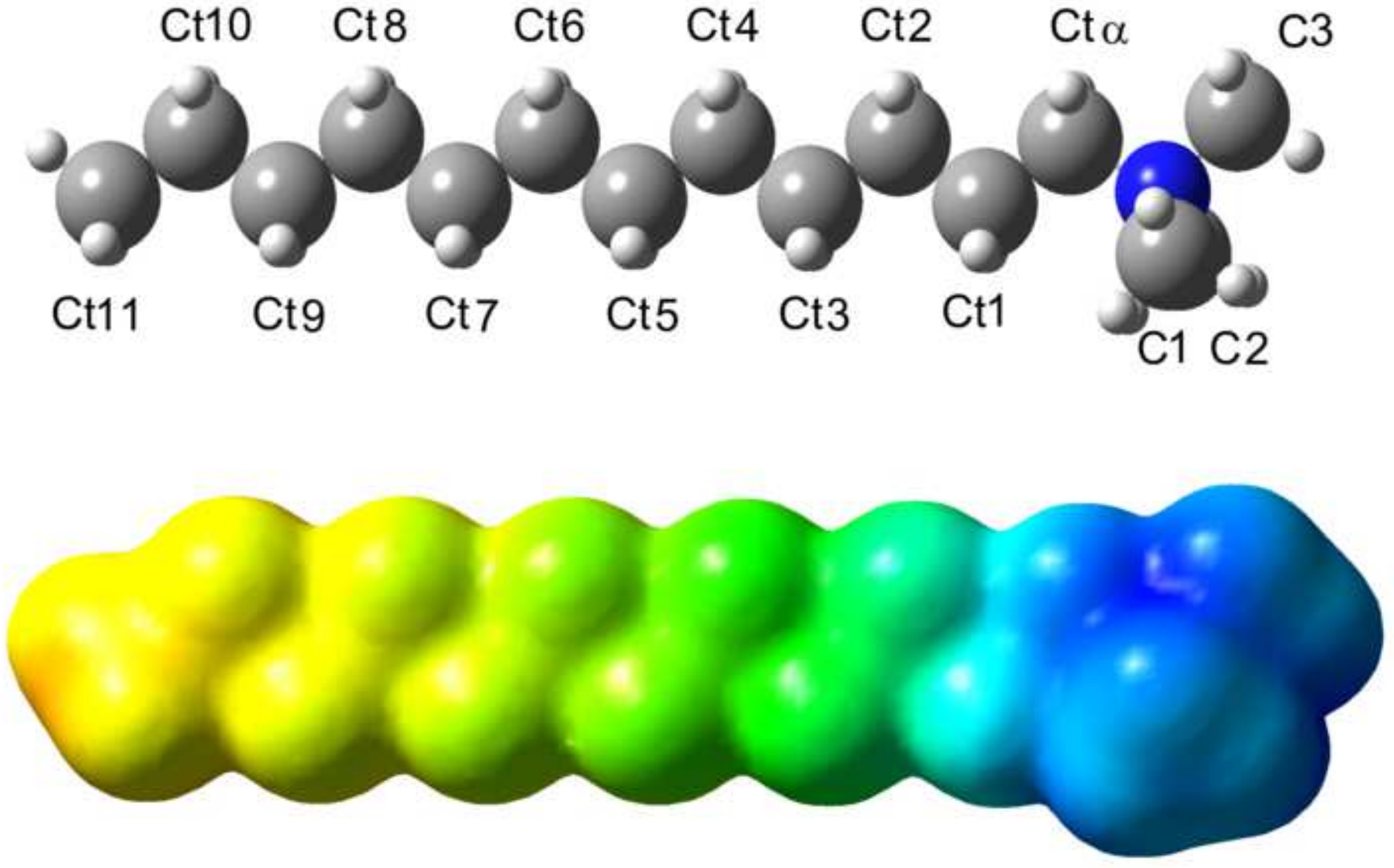

$0 \mathrm{kcal} / \mathrm{mol}$

$127 \mathrm{kcal} / \mathrm{mol}$ 


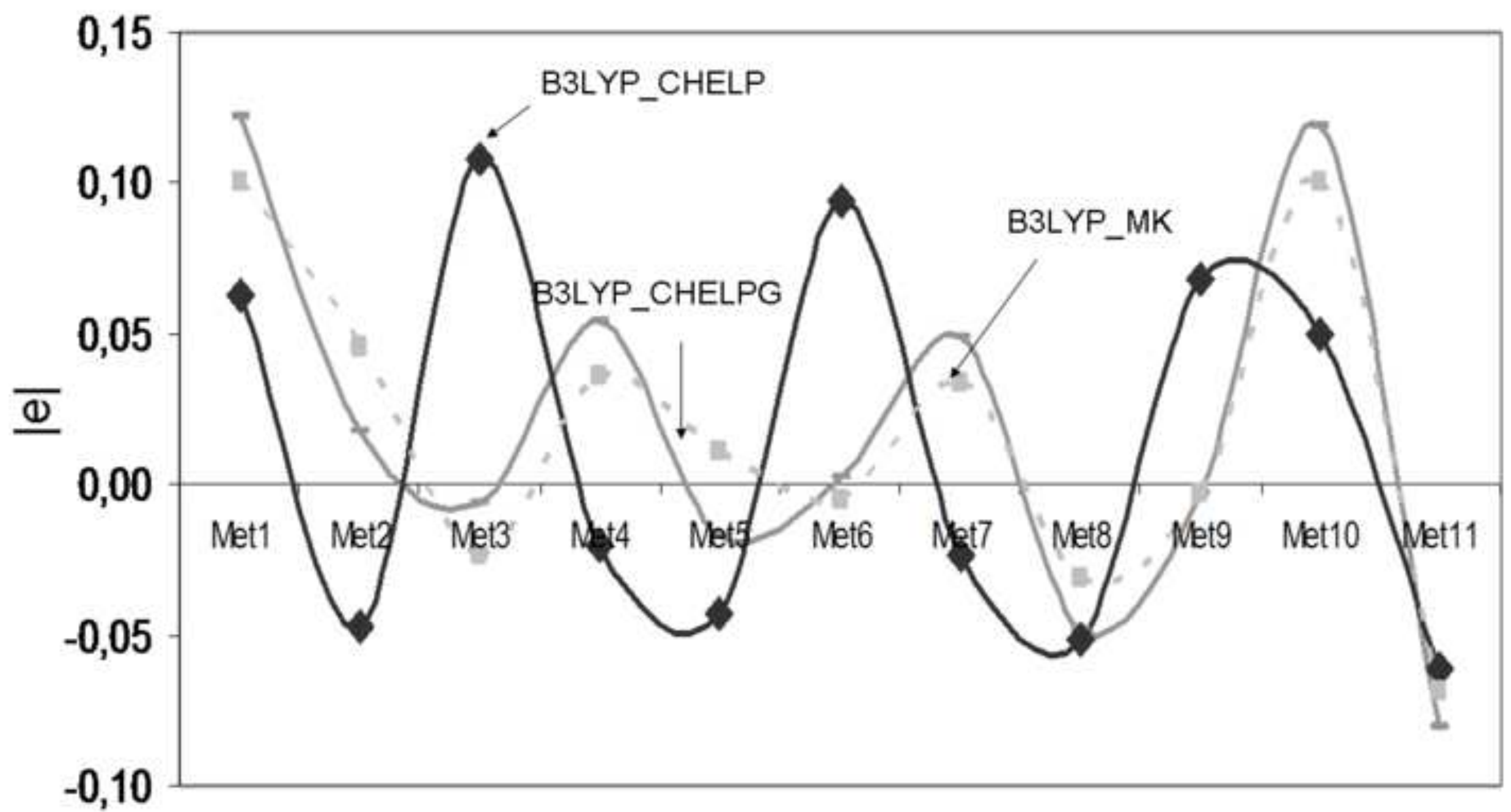




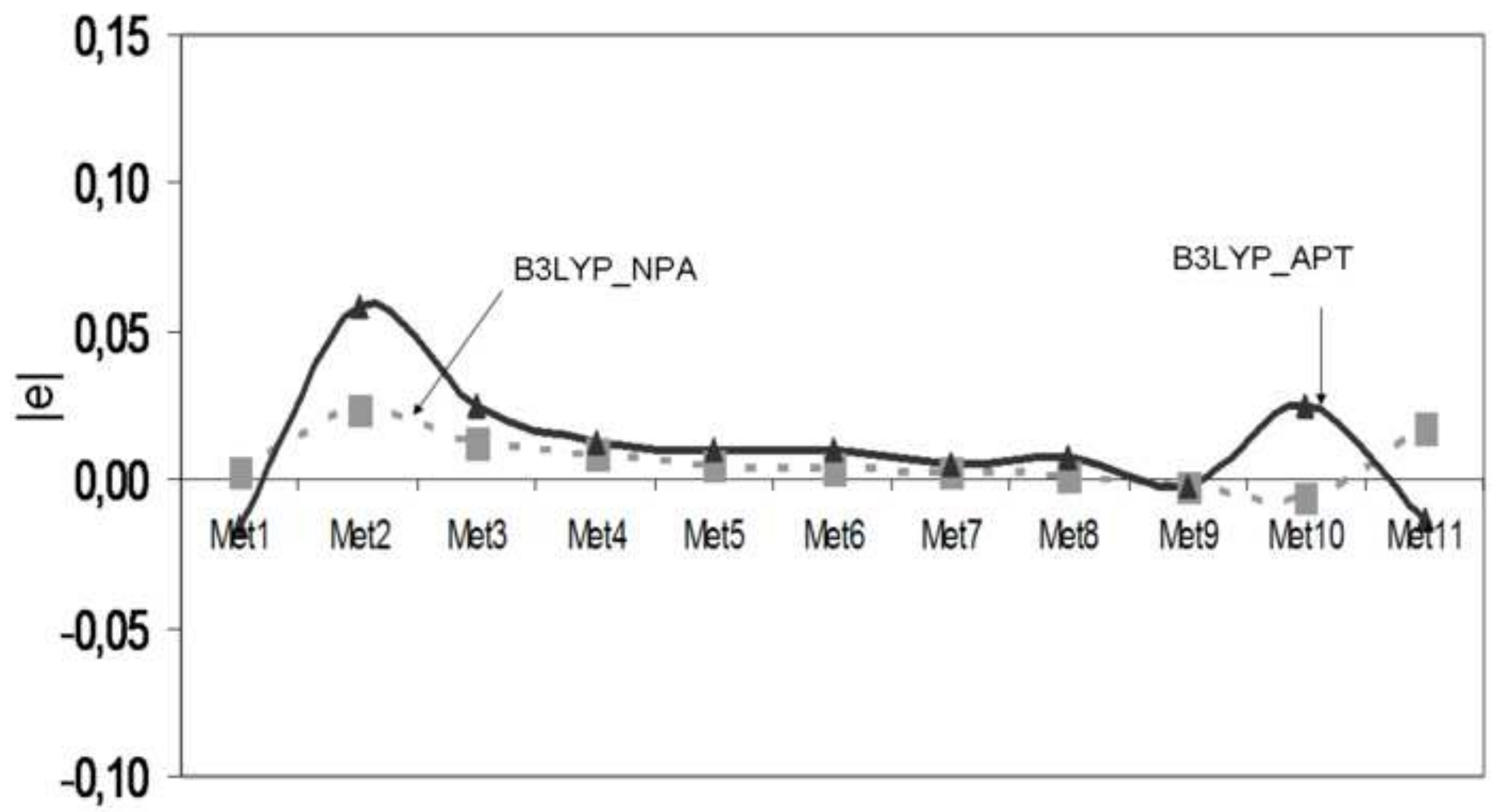




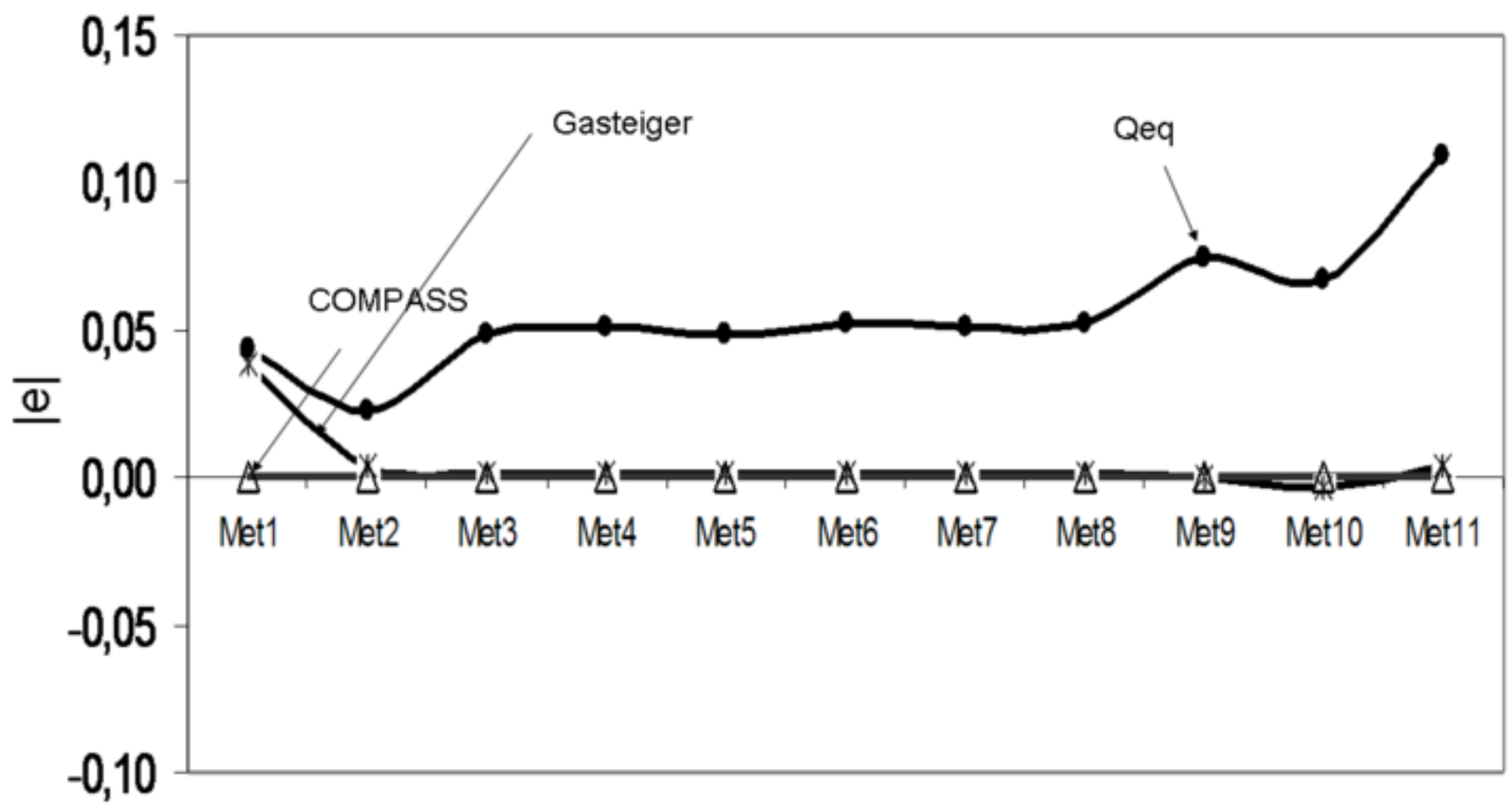

